\title{
Investigation on form and energy use of the rural residences in Beijing and surrounding cold areas under the self-sufficiency perspective
}

\author{
Wei $\mathrm{Gao}^{1}$, Mei Zhao ${ }^{2, *}$, and Huihua $\mathrm{Li}^{3}$ \\ ${ }^{1}$ Beijing Jiaotong University, School of Architecture and Art, Haidian District, Beijing, China \\ ${ }^{2}$ Beijing Institute of Technology, School of Design and Art, Haidian District, Beijing, China \\ ${ }^{3}$ ARTS Group Co.Ltd., No.111 Bada Street in Suzhou Industrial Park, China
}

\begin{abstract}
As a design theory on energy-saving housing, Self-sufficiency house is suited to the environment conditions of cold rural areas in China. Investigation on the rural residence form and energy use is the important foundation to carry out the research and design practice on self-sufficiency house. Taking Beijing and its surrounding rural areas as target, the paper combs current situation and technical requirements of rural residence based on self-sufficiency perspective. After surveying general residential condition and data, it analyzes the form, function, energy use and heating technology of rural residence, which will provide basic data and reference for post-study.
\end{abstract}

Keyword: Rural residence, Self-sufficiency, Form, Energy use, Beijing.

\section{Introduction}

The "autonomous house for self-sufficiency" was a greenhouse design theory raised by Alex Pike from Cambridge University in 1971, whose original intention was to develop a self-serving system for residences to reduce dependence on limited regional energy sources. Pike's students, the couple of Robert Vale had proceeded continued research on "autonomous house for self-sufficiency" from 1975 and published a series of works such as "The Autonomous House Design And Planning For Self-Sufficiency"(1975) ${ }^{[1]}$, "Green Architecture: Design for A Sustainable Future"(1996) ${ }^{[2]}$, "The New Autonomous House" $(2002)^{[3]}$. They discussed the definition and constructional method of "autonomous house for self-sufficiency" in the books including how to provide hot water and auxiliary heating by solar energy, achieve indoor power supply with solar and wind energy, store indoor heat through building envelope, receive rainwater and recycle reclaimed water, realize domestic waste degradation and compost and so on. They also carried out a series of design and construct practices of autonomous house for self-sufficiency in parts of England, New Zealand and elsewhere.

\footnotetext{
*Corresponding author: maezhao@qq.com
} 
Rural areas of cold climate in northern China are huge demographically and geographically. The backwardness of rural municipal infrastructure and inconvenience of energy resources supply have been a problem for village residents longtime due to the geographical environment and economic conditions. Based on the technical characteristics of self-serving energy, resource and infrastructure, reducing dependence on municipal supply, the autonomous house for self-sufficiency is effective method of energy-saving suited to the rural environment conditions and is practically important to application and promotion ${ }^{[4]}$. Investigation on the rural residence form and energy use is essential because both the design and construction of self-sufficiency house should fully meet the needs of rural production and living, fit to rural living habits and reflect characteristics of rural environment in cold area. Take the case of rural residence in Beijing and surrounding cold areas, it conducts indepth investigation and analysis on residence form and energy use, in order to provide reference for relevant research and practice.

\section{Research content and general situation}

The study selected Jiuxian village and Guantou village in Yanqing District of Beijing, Xizhuang village in Yuxian County of Hebei, and Liuzhuang village, Beihao village, xiaoningkou village and Shenjiaying village in Bazhou of Hebei for in-depth investigation. 120 questionnaires were distributed, and 22 households were interviewed and surveyed.

According to the survey, the residences in Beijing and its surrounding rural areas are completed by horizontal combination with bays as the basic unit, which is in good integrating degree with the technical characteristics of "autonomous house for self-sufficiency" of the couple of Robert vale. ${ }^{[5]}$ But overall it is slightly single and has room for optimization and improvement. Three-bay and five-bay residences are the most common, accounting for $27.3 \%$ and $45.5 \%$ respectively, and four-bay and six-bay residences account for a small part. In terms of scale, there is a gradual increase in the number of residential bays. The houses built in the 1970s and 1980s are dominated by three-bay residence. Afterwards, due to the increase of family population, the proportion of five-bay residences increased significantly from the 1980 s to the 1990 s, and the bay combination has gradually become more flexible. In the late 1990s, even-numbered bays residences such as four-bay residence and six-bay residence began to appear, indicating that the composition of rural households has gradually become more differentiated. In order to meet the needs of different families, the number of bays has become more and more flexible. In recent years, new houses are developing in the direction of five or six bays (Fig. 1).

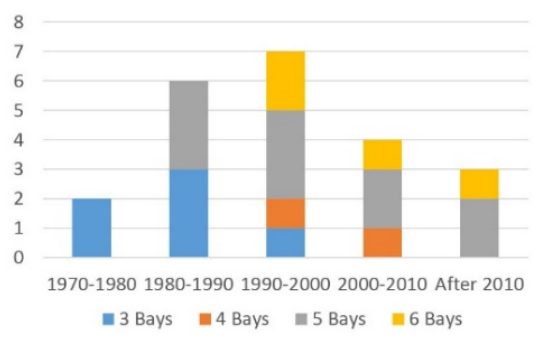

Fig. 1. Relationship between construction time and the number of bays. (Left)

In terms of depth, most of the early residence are one-entry. After 2000, in newly residence, the proportion of two-entry residence gradually increased and became a dominant form. This reflects the gradual improvement of rural living standards. At the same time, the north rooms of the two-entry residence can be used as the climate buffer zone for the main rooms facing south, which has better thermal insulation than the one-entry residence, and is 
more conducive to the application of technical skills and the improvement of living quality(Fig. 2).

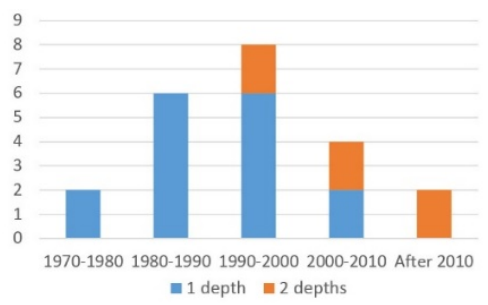

Fig. 2. Relationship between construction time and the depth size. (Right)

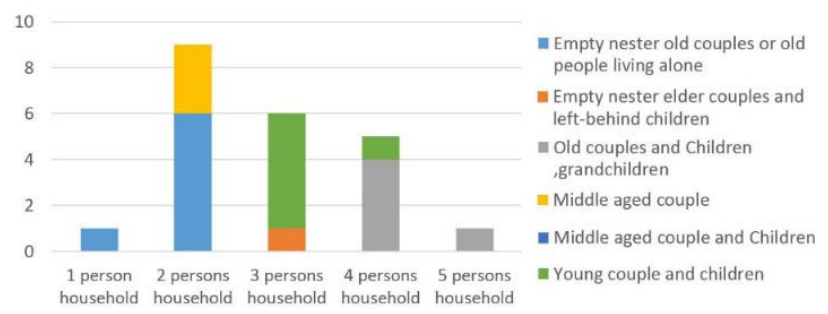

Fig. 3. Number of residences with different population.

In terms of household demographics (Fig. 3), two-person household make up a large proportion (41\%), with empty-nesting elderly couples predominating. In rural areas, it is common for young adults to go out to work and most of the permanent residents are empty nesters, who usually live in the brick house ${ }^{[6]}$. Thus some rooms in the house are often vacant and unoccupied without heating facilities. Only when young people return home from work on holidays, will they place removable stoves in their rooms to keep warm. This phenomenon requires that the design of energy-efficient houses should put forward specific plans for the design of room heating technology according to different usage situations, in order to achieve reasonable distribution of heat in houses and improve heating efficiency. This phenomenon requires that the design of energy-efficient housing should propose solutions for the technical design of room heating according to the different use cases, so as to achieve a reasonable distribution of heat in the housing and improve heating efficiency.

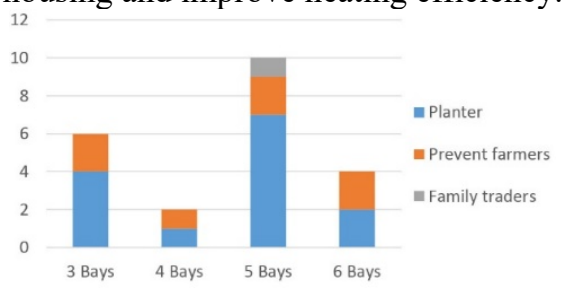

Fig. 4. Number of homes in different production modes. (Left)

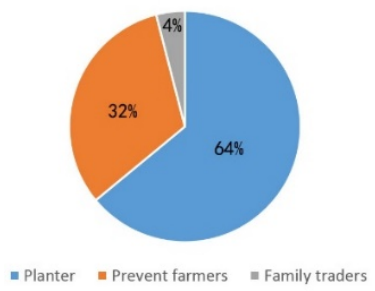

Fig. 5. The proportion of residences in different modes of production. (Right) 
In terms of household production methods (Fig. 4, Fig. 5), agricultural farming accounts for the largest proportion of households, followed by livestock and poultry farming, with small businesses accounting for the smallest proportion of production methods. This is a mixed production method that farmers and commercial households often grow crops on the side as well. The large proportion of growers indicates that there is a good source of biomass energy in the countryside in the form of straw crop production waste, and rural homes should make full use of such a high-quality resource. The large proportion of cultivators indicates that there will be corresponding straw-based crop production, a good source of biomass energy, waste in the countryside. Therefore rural dwellings should make full use of such a high-quality resource.

\section{The basic dimensions and proportions of the residences}

Based on the statistics of 22 key cases, the relationship among residential bays, depths, story heights, and area ratios can be obtained.

The bay of the basic residential unit is about 3 meters, and the fluctuation range is not large. This is the empirical value obtained from the long-term construction of rural residences, suggesting that the bay size of the energy-saving design can consider the corresponding modulus, such as 3 meters, 3.3 meters, 3.6 meters, 3.9 meters, etc. The depth of the single span of the residence is about $5-6 \mathrm{~m}$, the depth of the double spans is up to 7 meters, and the depth of the south-facing room is in the range of $4.5-6 \mathrm{~m}$. As shown in figure (Fig 6), the bay depth broken lines of single-span and two-span deep rooms are roughly parallel, and the ratios are about 3:5 and 7:5, respectively, but the ratio between the bay and the south-facing room depth is quite different. The floor height of houses is mainly in the range of $3-3.6 \mathrm{~m}$, the ratio of depth to floor height is about 1.5-2.2, the ratio of southward room depth to floor height is in the range of $0.9-1.7$, and the three broken lines are basically parallel (Fig. 7). The area of single-span basic unit is roughly 14-20 square meters, the area of individual units reaches 26 square meters, the area of double-span basic unit is 20-30 square meters, and the maximum is 34 square meters. The two broken lines of the double span basic unit remain parallel, and the ratio of the south-span depth area to the total area is about 3:5 (Fig. 8).

The above index data has been used to date due to adaptation to rural conditions. After calculation, it is basically consistent with the control indicators such as surface area coefficient and shape coefficient in the "Thermal Design Manual of Passive Solar House" ${ }^{[7]}$. It can be used as a suitable spatial scale unit for reference in the design of rural self-sufficiency house. When the residence has more than 3 bays, it should be considered that arranging some bays on the second floor to reduce the shape coefficient and the heat dissipation surface on the north side, besides saving land.

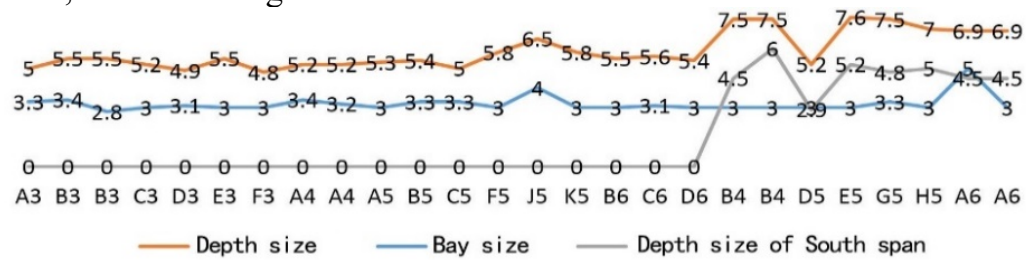

Fig. 6. Dimensions of basic unit bays and depths.

(The letter on the abscissa is the serial number, and the number is the bay number, same below). 


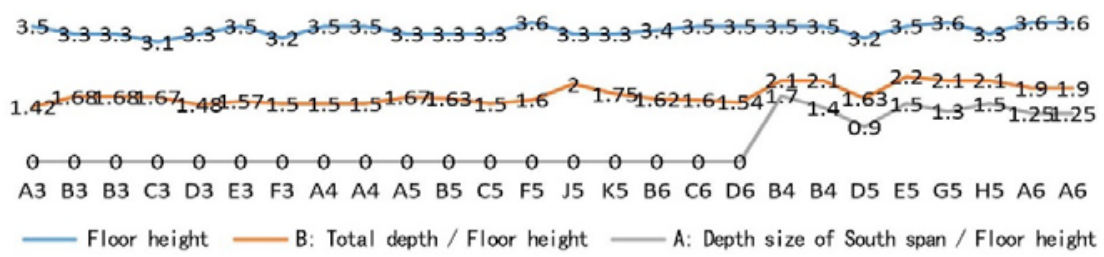

Fig. 7. Floor height and depth dimension of the basic unit.

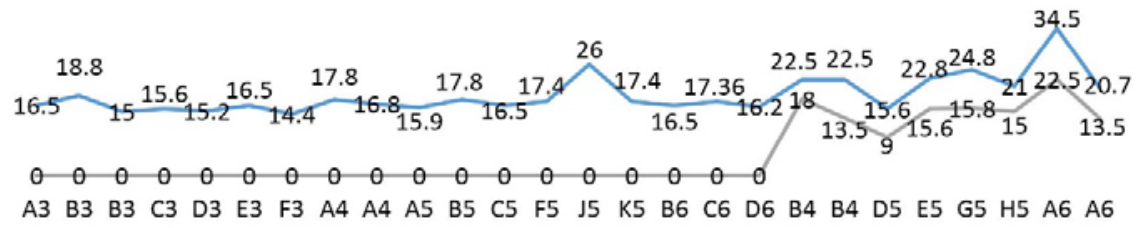

- Total area $\quad$ Area of South span

Fig. 8. Basic unit area diagram.

\section{Characteristics of residential function}

The characteristics of residential function refers to the type, area and quantity attributes of each functional room, which are closely related to residential energy use situation, thermal insulation technology, and heating mode, etc. ${ }^{[6]}$

According to the survey, the area of three-bay residence is basically around $80 \mathrm{~m}^{2}$ with 5 to 6 rooms; Larger fluctuation shows on the area and the quantity of rooms of four-bay and above residence, such as $110-150 \mathrm{~m}^{2}$ with 9 to 13 rooms, $110-150 \mathrm{~m}^{2}$ with 7 to 11 rooms and 130-200 $\mathrm{m}^{2}$ with 9 to 11 rooms, indicating that residents will determine the residential area basically according to the family actual demands and no particular pattern. The quantity and area of three functional rooms, central room (living room/lobby), bedroom, production room, occupies the majority of the residence and is the main function of the rural residences. About half of the residences equipped with independent kitchen or dining room, and the area is about 6-20 $\mathrm{m}^{2}$,with 1-2 rooms; Each residence equipped with one lavatory, most without water closet, a few of them are indoor bathroom with closetool, wash basin, shower area, the area are about 7-10 $\mathrm{m}^{2}$ (Fig. 9, Fig. 10).

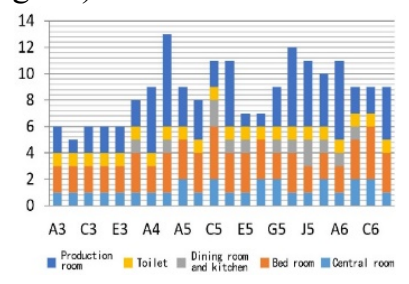

Fig. 9. Quantity of functional rooms of rural residences. (Left)

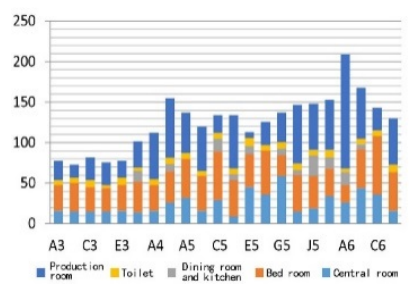

Fig. 10. Area of functional rooms of rural residences $\left(\mathrm{m}^{2}\right)$. (Right) 
In terms of main function, the area of most central room in three-bay or four-bay residence is about $16 \mathrm{~m} 2$ each room, but the area of five-bay or six-bay residence fluctuates significantly. The reason is that some central rooms have been simplified to lobby, the transitional space like porch in entrance, and the area shrinked, while the other gradually turn into complete living room with the area increased and occupying two bays. Concerning the two trends, the design of self-sufficiency house should arrange the lobby and living room properly to meet the requirements of spatial transition and specific using.

In terms of bedroom, three-bay or four-bay residence usually has 2-3 bedrooms with the area about $35 \mathrm{~m} 2-40 \mathrm{~m} 2$, average area of each bedroom is $18-20 \mathrm{~m} 2$; The area of five-bay or six-bay residence fluctuates significantly, and more of them have 2-4 bedrooms, average area of each bedroom is about $20 \mathrm{~m} 2$. The majority of residences have at least one bedroom with kang, and usually have the highest utilization rate, with the same functions as living room, dining room and even kitchen, while the bedroom without kang is just use for rest. Kang had been widely used in rural residences and has already become a life style ${ }^{[8]}$. Only new houses have independent living room and do not use bedroom with kang as living room. In actual use, most residences only use 1 or 2 bedrooms and mostly are kang rooms, and many other bedrooms are left vacant as temporary storerooms. Thus, arranging 4 bedrooms in Selfsufficiency house could satisfy the family needs, and some bedrooms could transit functions flexibly.

In terms of production room, storerooms are usually arranged in growers' house. Farm tools and grain storerooms often occupy the west side of the house room, the west wing or the north wing and daily-using articles storerooms are often flexibly arranged in lobby or north corner of room; farmers usually arrange livestock sheds and a few storerooms for enclosing livestock and storing farm tools; Merchants arrange small shops and storerooms. The area and quantity of storeroom fluctuate significantly according to actual using. In general, production space with large area should be detached from the main body of residence, and small storerooms could be arranged in the north of the basic unit or temporary use the vacant bedroom.

\section{Energy consumption and heating technology}

A heating technology survey of 22 typical residences found that the heating technologies used in rural residences include independent kang (a heatable brick bed in North China), stove-linked kang, stove, conventional heating, double-layer exterior windows and doors (similar to small sunshine rooms) and solar water heaters, etc (Fig. 11). Some technologies are in a dominant position and are used more frequently, while others only play a supplementary role. However, a variety of heating technologies complement each other is the long-term heating strategy of most rural residences, and the types and the numbers of heating technologies for newly-built rural residences in the past 15 years are gradually increasing. This strategy can well learn from each other to make up for the shortcomings to achieve a reasonable distribution of heat, which provides a reference for the heating design of self-sufficiency house.

On the whole, about $80 \%$ of the residences use stoves; independent kangs and stovelinked kangs are also common, $68 \%$ and 50\% respectively; the use of conventional heating accounts for $32 \%$, and most of them are used in combination with stoves; $23 \%$ of the residences use solar water heaters; $9 \%$ of the residences have double-layer exterior windows, all of them come from wealthy families. The choice of heating technology is closely related to the economic level of the family. Most families with better economic levels choose stoves with low cost and high flexibility, and some also choose more costly and more complex heating technologies as supplements, such as double-layer exterior windows and solar water heaters; families with the second lowest conditions will choose Low-cost heating 
technologies such as kang to supplement; economically average families often choose lowcost stove-linked kangs, plus low-cost stoves, independent kangs or conventional heating as supplements.

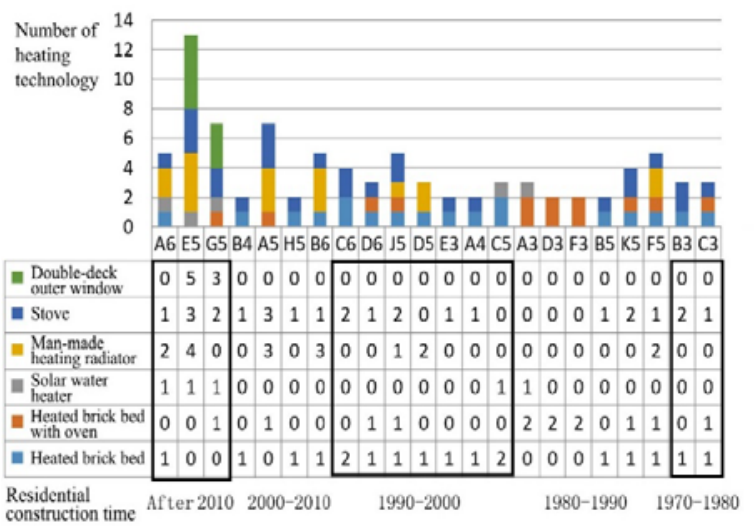

Fig. 11. Investigation on heating technology of some rural residences in Beijing and surroundings.

Specific to the rooms with different functions, central rooms are often used as halls and heating technology is rarely arranged, except for wealthy families. Master bedrooms and second bedrooms are equipped with heating technology, and the common ones are independent kang, stove-linked kang, stove or radiator. The common heating technology in the master bedroom is a combination of independent kang and stove. Usually, the heat generated by cooking and boiling water from the stove is directly used to heat the room through the radiator, and the kang is only heated when the weather is particularly cold. The independent dining room of a few residences is equipped with a stove or stove-linked kang. In addition to the use of solar water heaters to provide hot water in the indoor toilets, no other heating technology will be arranged. It can be seen from the analysis that the main function rooms with high frequency of use generally have two heating technologies. One is that the dominant technology which is often used, and the cost is generally lower. When the dominant technology cannot meet the requirements, high-cost supplementary technology is used.

\section{Conclusions}

The form, functional component, energy use and heating technology of rural residences are gradually formed in the long-term life and production of rural areas. It not only has the basis of physical environment and economic conditions, but also the continuation of lifestyle, customs and traditional culture. It is the basis of Self-sufficiency house design. In recent years, rural areas in northern China represented by Beijing have vigorously promoted the improvement and innovation of rural energy use and heating technology. Coal-to-electricity technology has replaced coal-fired heating, and conventional kang technology has gradually been replaced. In the new stage of rural energy-saving housing construction, it is necessary to actively explore the establishment of new self-sufficiency technologies such as solar kang, additional sunshine room, and bio-energy saving based on full investigation and analysis of the actual situation of rural residence, so as to form an energy-saving design method that meets the technical requirements of the times and is conducive to the continuation of rural traditional customs and culture.

Supported by Beijing Municipal Social Science Foundation (15SHB014) and The National Key R\&D Program of China (2018YFD1100205) 


\section{References}

1. Brenda Vale, Robert Vale. The Autonomous House Design and Planning For SelfSufficiency [M]. London: Thames\& Hudson, 1975.

2. Brenda Vale, Robert Vale. Green Architecture: Design for a Sustainable Future [M]. London: Thames\& Hudson, 1996

3. Brenda Vale, Robert Vale. The New Autonomous House [M]. London: Thames\& Hudson, 2002.

4. Zhang Jinliang, Gao Wei. The Implications of Autonomous House on Rural Ecological Residence in Domestic [J]. Huazhong Architecture, 2014, 32(10):14-18. (In Chinese)

5. Gao Wei, Zhang Jinliang. Study on the Design of Rural Houses in Cold Region in Hebei Province on the Idea of Autonomous House for Self-Sufficiency [J]. Huazhong Architecture, 2016, 34(05):65-69. (In Chinese)

6. Li Huihua. Research on Architecture Design of "Autonomous House" in Cold Rural Area Based on Technology of Heating [D]. Beijing Jiaotong university, 2016. (In Chinese)

7. Li yuanzhe. Thermal design manual of passive solar house[M].Beijing: Tsinghua university press, 1993. (In Chinese)

8. Gao Wei, Hu Min, Jin Xiaojuan .Analysis on the Current Rural Construction Model in China based on Participation Roles [J]. Urban Development Studies, 2019, 26(03):2127+32. (In Chinese) 